\title{
Energy balance and cancer risk at the cellular and whole organism level: modification by metformin
}

\author{
Michael Pollak \\ From Metabolism, diet and disease \\ Washington, DC, USA. 29-31 May 2012
}

It has long been recognized that dietary restriction (DR) can inhibit carcinogenesis. Recent work has not only clarified the mechanisms involved, which involve the effects of DR on circulating hormones and cytokines, but also demonstrated molecular characteristics of tumors that determine the extent to which they are influenced by variation in host energy intake. Importantly, we and others have also demonstrated that a subset of tumors are growth-stimulated by excess caloric intake, and provided strong circumstantial evidence that hyperinsulinemia is one of the mediating factors. Metformin, a biguanide used in cancer treatment, has been associated with reduced cancer risk in some hypothesis-generating pharmacoepidemiologic studies. Laboratory studies have provided evidence for some antineoplastic activity. However, this activity is confined to subpopulations including subjects who are obese and/or hyperinsulinemic. Laboratory models suggest that metformin may act in this context because it is well-known to reduce hyperinsulinemia as a consequence of its reduction of gluconeogenesis and hyperglycemia. At the cellular level, metformin acts to inhibit oxidative phosphorylation, and this may provide an additional mechanism that could operate in the subset of cancers or at-risk tissues that express the cell surface transport molecules required for metformin entry to cells. The ATP deficiency induced by metformin may have little effect on some cells, an AMPK-dependent cytostatic effect on others, and still others may suffer an energetic crisis and necrotic death. Current research is providing additional details and mechanistic details underlying these actions, defining the subsets patients for which biguanides may be useful in cancer prevention or treatment, and

Department of Oncology, Lady Davis Institute for Medical Research of the Jewish General Hospital and McGill University, Montreal, Quebec, Canada defining relevant doses for potential new indications. Investigating the possibility of 'repurposing' metformin for applications in oncology is ongoing as laboratory and translational research ield data that will help to optimize clinical trial design.

Published: 1 June 2012

\section{doi:10.1186/1753-6561-6-S3-O21}

Cite this article as: Pollak: Energy balance and cancer risk at the cellular and whole organism level: modification by metformin. BMC Proceedings 2012 6(Suppl 3):O21.
Submit your next manuscript to BioMed Central and take full advantage of:

- Convenient online submission

- Thorough peer review

- No space constraints or color figure charges

- Immediate publication on acceptance

- Inclusion in PubMed, CAS, Scopus and Google Scholar

- Research which is freely available for redistribution
() Biomed Central
C Biomed Central 